\title{
Understanding resistance to resilience in coastal hazards and climate adaptation: three approaches to visualizing structural and process obstacles, opportunities and adaptation responses.
}

\author{
Donald D. Robadue, Jr., Ph.D. \\ Coastal Resources Center, Graduate School of Oceanography, University of Rhode Island \\ robadue@uri.edu
}

\begin{abstract}
The US state of Rhode Island (RI) offers a unique case for examining the conditions that hinder or facilitate coastal resilience efforts, due to its small size, active coastal program, and dynamic engagement of stakeholders. A five-decade corpus of information on hazard events, studies, plans and policies, and a database of more than 40,000 RI Coastal Resource Management Council (CRMC) permit decisions helps reveal patterns of decision-making related to coastal resilience. A social network map traces RI stakeholder engagement revealing hidden areas of resistance to resilience policies. Content analysis of documents and press coverage of decision-making in just one critical coastal area reveals 71 types of obstacles articulated by property owners and authorities. Current RI plans and studies are biased toward public engagement, filling information gaps, and designing new adaptation options. Deeper structural, financial and institutional sources of resistance to resilience remain and continue to be difficult to address.
\end{abstract}

\section{Introduction}

The current environment surrounding coastal hazards decision making is more complex and presents more ambiguity than at any time in our recent history. Politically, there are more players fighting for the ability to develop fewer coastal properties with ever increasing regulation on their use. Climatic changes are projected to impact coasts and coastal societies considerably, in new ways that have not been experienced by human societies, presenting an additional layer of complexity for decision and policy makers, coastal businesses, and coastal property owners. When faced with uncertain options, holding on to the status quo as long as possible is seen as the most viable path forward. Fortunately, there are numerous places and moments in the US where the agenda setting process for natural hazards issues leads to the adoption and implementation of forward looking policies. We explore the nearly five decades of experience in the State of Rhode Island to help identify and understand the enabling conditions that have resulted in past and recent important advances in coastal hazards.

Historically, coastal development design and construction requirements are focused on preventing loss of life and ignore the possible range of building damage states after a disaster and measures of postdisaster usability. Little action is taken to rehabilitate older structures that are often the most vulnerable to damage [1]

Coastal states such as Rhode Island are considering a wide range of possible protective actions, however we have a limited understanding of how to quantify the willingness and ability of communities to adopt these new behaviors in order to adapt to storm hazards. We continue to struggle to improve the adoption rate of protective actions by communities. [2, 3, 4]

Decisions to carry out mitigation actions are complicated, and can depend on a variety of factors involving individuals or policies. Mundorf et alia note from a psychological perspective that

"Helping individuals to continue to progress is likely to continue to increase their support for disaster and adaptation-related public policies as well. We have the tools to communicate change, but it takes a network of change agents and readiness at all levels to design and disseminate effective messages." [5]

This contributes to an "adaptation deficit" [6] whereby threatened communities and other institutional actors often fail to take an appropriate level of actions to adapt to climate change threats, including sea level rise and coastal storm hazards.

Low levels of institutional resilience---"the degree to which these networks plan for, learn from, and operate to address threats, build capacity, and act through coordinative vehicles like planning" ---is a serious barrier set up by the greater difficulty in assembling the resources needed to "infuse targeted assistance to communities and associated stakeholders beforehand in anticipation of recovery benefits that remain unmeasured." [7].

Our research goal is to understand the obstacles, incentives, and changing perspectives on adaptation to coastal hazards by property owners and within coastal areas, focusing on their interactions with public policy debates regarding coastal resilience. The order-ofmagnitude improvements neded to improve 
preparedness for coastal hazards requires a deeper understanding of these challenges. A post-Hurricane Sandy analysis by the U.S. Army Corps of Engineers noted that: "...the authors of this report are unaware of any literature that attempts to quantify the ability of a community to transform and adapt new functions in response to a disturbance." [2]. Our project aimed to help fill this identified research gap, building on the barriers to adaptation research by Moser and Ekstrom [8], Deegan et alia, [9]. Mileti [10] and Birkland [11].

We hypothesize the following to be among the important barriers to adoption of appropriate mitigating behaviors: 1) decision-makers lack full understanding of the threats faced; 2) conflicting incentive structures create counterproductive behaviors or otherwise impede coordination among groups; 3) established patterns of behavior are difficult to overcome; and 4) governance systems can hamper adoption of policies to improve resilience.

The coastal state of Rhode Island has one of the earliest coastal management laws in the US (1971) and earliest federally approved programs (1979). This provides more than five decades of planning and regulatory experience to draw upon in analyzing factors that contribute to or impede progress.

\section{The pursuit of coastal resilience policy in Rhode Island}

The problem, policy and politics streams surrounding natural hazard impacts and mitigation are intertwined over time. Burby [12] identifies Rhode Island as only one of ten states with "both state local government building code and comprehensive plan requirements", thus having among the stronger governance settings for achieving more resilient communities and economy. URI researchers and extension staff have worked with citizens, businesses, municipal, state, and federal actors for the past halfcentury, trying to overcome resistance and obstacles to reducing vulnerability to hazards. Such robust planning and advisory capability itself may not lead to policies that contribute to overall resilience. Contradictions abound in attitudes and policy. A case study of Washington, North Carolina, by Berke et alia [13] found that the city's hazards plan made a positive contribution by seeking to reduce development in the 100 year flood plain, but didn't incorporate sea level rise. The city's community development plans were in fact aimed at increasing the amount of physical development in hazardous areas not restricting it.

The Hurricane of 1938 remains the most referred to storm event for Rhode Island. It is the subject of periodic retrospectives in the press and the largest flooding footprint throughout the state from a historical storm.
More recently, Hurricane Carol in 1954 led to the 1957 "Hurricane Survey Interim Report" by the US Army Corps of Engineers. The Corps proposed a variety of hurricane barrier configurations for Narragansett Bay. This plan in turn led to the construction of the Fox Point Barrier in 1960-1966, very close to the City of Providence in the headwaters of the Bay and the rejection of other proposals that would have cut off the entire bay from the Atlantic Ocean.

Natural hazards policies in RI date to the creation of the National Flood Insurance Program in 1968, the Rhode Island Coastal Resources Management Council in 1971, the Federal Coastal Zone Management Act of 1972, the John Chafee Coastal Barrier Resources Act of 1982, and numerous modifications and reauthorizations since then. FEMA's Project Impact and its successors since 1997 spurred the creation of local multi-hazard mitigation plans. URI researchers and extension staff have been active at least since the 1970s in documenting coastal processes and storm damage. Natural hazards were also a focus of the original RI Coastal Management Program document in 1979 and the Salt Ponds Special Area Management Plan adopted in 1984.

A major concern for planners and researchers concerned about resilience in Rhode Island is the absence of recent memory of a major disaster that affected the entire state and galvanized a major response similar to Hurricane Carol in 1954. Becker [14] found the absence of memory to be a major reason for the effectiveness of recently developed highly detailed computer simulations such as "Hurricane Rhody", which he used to facilitate scenario planning in the Port of Providence, Rhode Island. "The problem of hurricane and sea level rise risk for the port of Providence, in itself, is very difficult to define and bound. Providence has experience numerous major hurricanes (e.g., 1817, 1885,1938 , and 1954), there has not been such an event in recent memory. None of the participants witnessed such a major storm hit the area, though many could recall hurricanes with far less power." [14]

We identified 148 coastal storm events affecting Rhode Island since 1936 including floods, winter storms and hurricanes that likely generated localized coastal storm damage leading to private and public investments in physical shore protection. These storms generate pockets of continuing damage on top of chronic coastal erosion along the state's highly varied 420 mile coast, making it necessary for coastal managers to focus on highly localized problem solving and regulatory solutions.

Our own organization, the Coastal Resources Center (CRC) based at the Graduate School of Oceanography of the University of Rhode Island has been involved throughout its history. Subsequently Project Impact in the late 1990s led to CRC involvement in preparing 
municipal hazard mitigation plans for the municipalities of Pawtucket and Narragansett.

In summary, Rhode Island's experience with coastal flooding, storms and chronic erosion over the past eighty years led to substantial institutional reforms of the type currently recommended by leading experts. Some have involved large scale construction (the hurricane barrier protecting the City of Providence) and many others requiring site specific shore protection installations and solutions, with increasing preference given to non-structural approaches. Rhode Island has depended heavily on scientific studies monitoring and projecting shoreline change rates and more recently on sophisticated online services such as STORMTOOLS (http://www.beachsamp.org/stormtools/) that simulate likely damage to individual property owner, current and future risk due to coastal hazards, major hurricanes through the Hurricane Rhody simulation and dramatic sea level rise predictions.

In the following sections we examine the lived RI experience in three ways: looking for patterns in more than four decades of coastal development decisions (Section 3.1); mapping and exploring the expanding policy network for climate and hazard resilience (Section 3.2); and examining in close detail the content of resilience and hazard plans, studies, decisions and debates to reveal how stakeholders describe obstacles and barriers to attaining more resilient coastal development (Section 3.3).

\section{Documenting coastal resilience policy implementation}

\subsection{Insights from the coastal development permit data base: new versus intensifying uses}

The RI CRMC has prepared an evolving series of studies, policies, and regulations as part of its record of more than 40,000 permit decisions on development activities in Rhode Island's coastal zone. For this research, the full CRMC permit data base from 1971 to 2016 is compiled and analyzed for the first time to identify patterns of decision making during post-storm event recovery as well as implementation of hazard reduction policies found in both statewide regulations and special area plans. The searchable permit data system is online at http://www.crmcpermitdatabase.org/pads.

One particular area of concern for coastal resilience in Rhode Island are its commercial waterfronts. Providence Harbor, Newport Harbor and Wickford Cove, important commercial and recreation ports, have been the focus of numerous vulnerability studies and adaptation planning since the beginning of the 2000s.
There are ten types of permit decisions issued by the CRMC and its regulatory staff. Six of these lead to actual construction projects including administrative or routine projects that easily conform to CRMC standards, more complex projects which are reviewed and approved by full CRMC; applications for maintaining an existing structure; fresh water wetlands permits; projects related to ice damage, and a special set of permits issued to allow rapid repairs to storm damage from Hurricane Sandy in 2012.

The CRMC has placed a great deal of emphasis in recent years on providing early guidance and advice to applicants for coastal development. However, in the following analyses, only permits issued for actual development projects are included in order to reflect actual decisions and construction. This includes 28,203 permit decisions that relate to projects that are implemented.

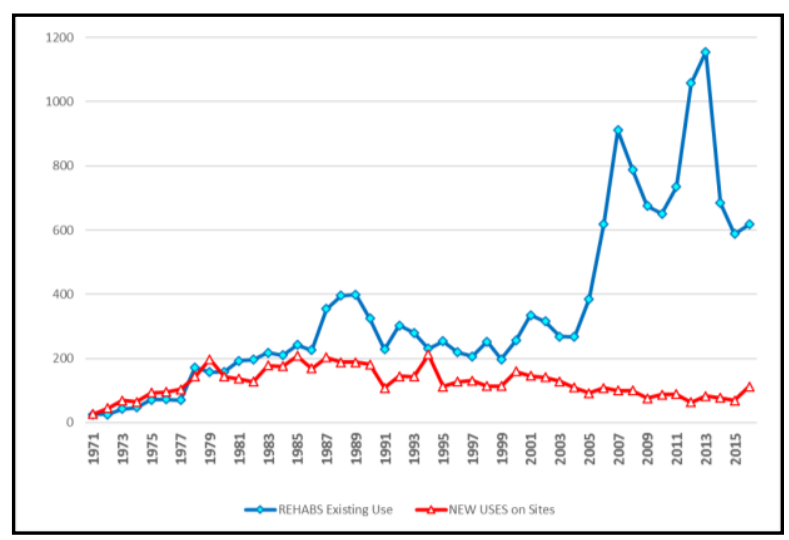

Figure 1 Annual comparison of CRMC assents that allow NEW USES on a coastal site (red line) compared to projects that maintain or rehabilitate (REHAB) existing development on coastal sites (blue line). Does not include preliminary determinations nor findings of no impact.

In addition to administrative categories the CRMC tracks permits by development activity type. There are 92 of these. In the 1980s new housing development dominated the attention of regulators. From a peak of 144 new units per year in the 1980s, the CRMC only approved 41 new homes on the coast in 2016. In recent decades the majority of CRMC housing decisions involve the rehabilitation or maintenance of existing buildings. An index to track these two trends is shown in Figure 1. The "REHABs existing use" trendline is composed of 15 permit activity types that involve rehabilitating or rebuilding coastal structures. The "NEW USES on sites" trend-line combines 17 activity types that involve new construction and coastal modification. 
NEW USES of the coast include new houses with onsite septic systems, new houses connected to sewers and houses with substantial alterations.

Quite simply, there are very few new development projects upon which to apply the increasingly progressive and protective policies and regulations in the Rhode Island coastal management program. In stark contrast, applications for REHAB projects that upgrade existing properties increased dramatically in the mid2000s and now dominate the CRMC's decision making workload. This growing intensification of the use of existing structures and property within alreadydeveloped coastal areas suggests that existing property owners, as well as prospective purchasers of existing shorefront homes are not retreating from the shore. The REHABilitation type projects in coastal sites are not subject to the most stringent regulations for elevation above base flood elevation as long as the proposed modifications to structures are less than 50 per cent.

\subsection{Shore protection and management decisions: geographic distribution of decisions.}

There are four development activity types directly related to shoreline erosion, sea level rise and flooding from storms. Between 1971 and 2016, the CRMC issued 2,882 permits in these categories, as shown in Table 1. We georeferenced the entire CRMC permit data base using ArcGIS 10.1 with the aid of the ArcGIS Maps add-in for Excel.

Table 1 Shore protection decisions 1971 to 2016 (Total $=2,882$ )

\begin{tabular}{|l|r|}
\hline Shoreline Protection Facilities/Repair & 1556 \\
\hline $\begin{array}{l}\text { Beach Nourishment/ Conservation } \\
\text { Restoration }\end{array}$ & 767 \\
\hline Shoreline Protection Facilities/New & 504 \\
\hline Shoreline Protection (Non-Structural) & 55 \\
\hline
\end{tabular}

An index using the four shore management and protection decisions was mapped this using the cluster analysis routine available through ArcGIS online. The result is shown in in Figure 2.

Each of these clusters of intense, continuous decision-making along the Rhode Island south shore have unique geomorphology, coastal development characteristics and patterns of exposure to erosion, waves, wind and storms. Ironically, forecasts of future damage to coastal property in high hazard areas suggest that current policies may actually prompt property owners to make minimal repairs and reinforce their

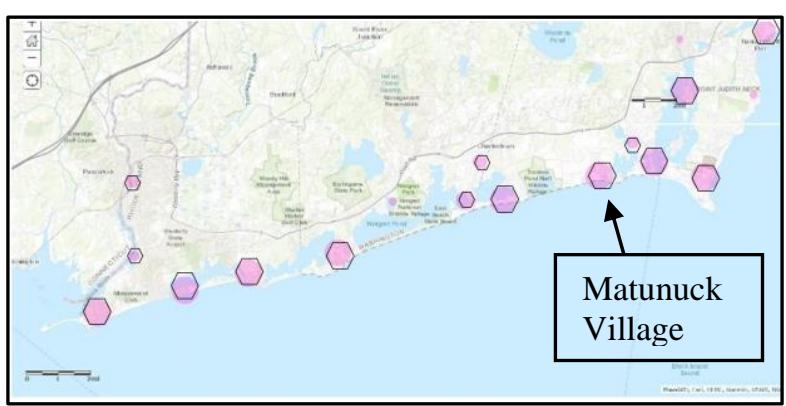

Figure 2 Location of clusters of shore protection permits on Rl's south shore, highlighting Matunuck Village.

desire to stay in hazardous shore areas. Small et alia [15] used a Coastal Environmental Risk Index (CERI) to analyze Matunuck Village (Figure 2), located adjacent to local and state operated public beaches. In recent years the village has become a hot spot for contentious shore protection decisions. (See Section 6). Small and his colleagues estimated damage to the 708 existing structures simulating a 100 year storm event with and without predicted sea level rise [15]. They found that "approximately $35 \%$ of the one and two story structures... are expected to be damaged from a 100 year storm event with no sea level rise... However, only $12 \%$ of these structures are estimated to be damaged more than 50\%." Since 50\% damage represents a critical threshold, very few property owners would have to rebuild to stringent standards. A significant degree of resistance to adopting resilience in coastal development is baked into the nature of coastal development patterns and existing policy affecting the state's 420 miles of coastline.

\subsection{Shore protection and management decisions: trends over time.}

In the 1970s more than half of the projects approved by the CRMC were for new hard shoreline protection facilities. With the adoption of the revised "Red Book" regulatory program document in 1983 beach nourishment and conservation became far more important. Since 2010 only 30 hardened shoreline projects have been approved. Repair to existing shore protection structures, 365 since 2010, continues to be allowed and accounts for about $40 \%$ of the total of current CRMC decisions. Non-structural shoreline protection is being tested but remains a very small portion of applications to the CRMC. There have been just 23 such projects since 2010.

Figure 3 shows the steady decline in approved applications for new houses in the high hazard defined here as the overwash zone of the Hurricane of 1938. 


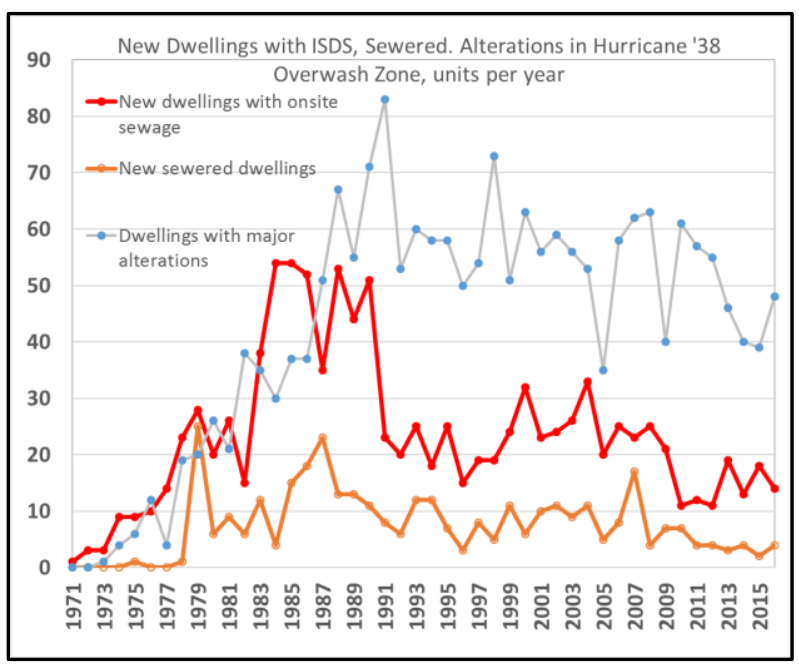

Figure 3 Declining trends in CRMC assents issued for new or altered dwellings in the high hazard zone as defined by the overwash area of the Hurricane of 1938.

In 2016 the CRMC approved only 4 new dwellings connected to municipal sewer service, 14 using onsite waste disposal, and 48 structures undergoing major alterations in the high hazard zone as defined by the Hurricane of 1938 overwash zone. This is a tiny proportion of the 4,991 dwellings and shore protection projects already approved in the hazardous overwash zone, and 13,952 structures presently located there. Figure 4 shows a segment of the Matunuck coastline illustrating structures now located in the high hazard zone (green shading) and the CRMC permits issued for new houses as well as shore protection projects within that zone.

\section{Recent coastal resilience policy and planning: opportunities for progress.}

Two years after Hurricane Sandy generated substantial damage to the South Shore and segments of Narragansett Bay, Rhode Island initiated several major studies, plans, data and tools including: the Rhode Island Hazard Mitigation Plan 2014 Update [16]; the inauguration of the RI Shoreline Change Special Area Management Plan [4]; the initiation of work on STORMTOOLS [17]; and the establishment of the Rhode Island Climate Change Coordinating Council. Post-Hurricane Sandy funding along with resources from Rhode Island Sea Grant and Rhode Island state agencies has helped support these efforts. This period also represents a transition in approaches to public engagement. The 2014 Update to the Hazard Mitigation Plan led by the RI Emergency Management Agency

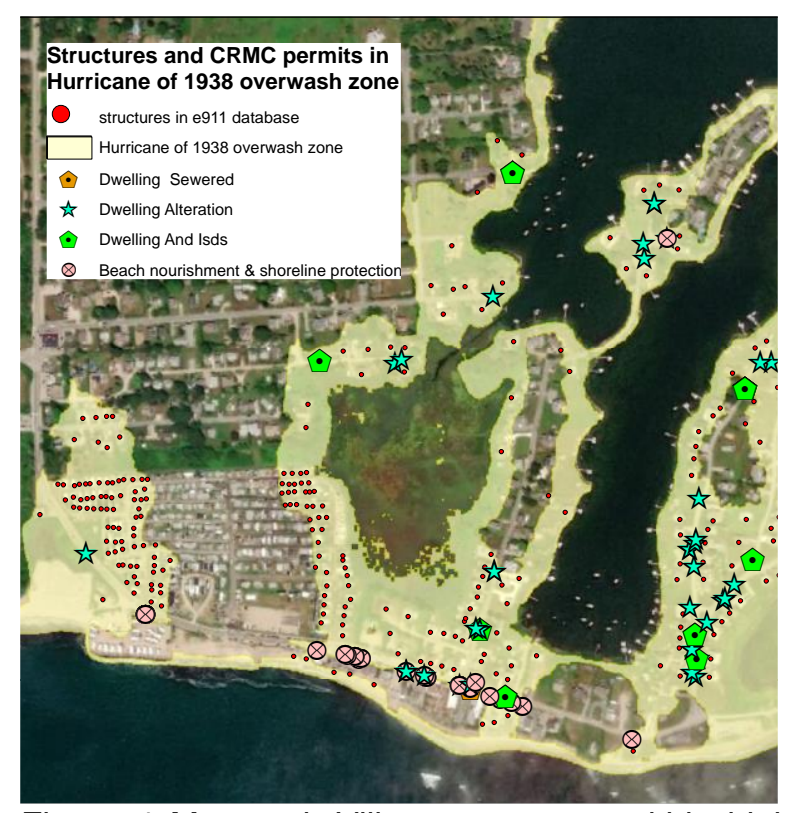

Figure 4 Matunuck Village structures within high hazard zone (overwash from Hurricane of 1938)

Notes: Coastal development since 1971 is largely within the zone of impact of the storm surge from the Hurricane of 1938 (yellow). Shore protection actions were sought by 120 individuals and businesses who carried out 211 projects (pink circle $\otimes$ ) in the village area. Many new and altered dwellings have been permitted within the Hurricane overwash zone by the CRMC, within its narrow 200 foot primary jurisdiction (blue stars is and, green $\bullet$ ).

(RIEMA) received written comments from only 13 individuals, mainly representing government agencies. RIEMA relied upon an online survey questionnaire that yielded only 70 responses, also principally from government officials. [16, p. 22].

In sharp contrast, the 2018 RI Shoreline Change Special Area Management Plan (Beach SAMP) [4] led by the CRMC engaged upwards of 1000 individuals in more than 30 public events, as well as made active use of an interactive website to keep the public informed about the years-long planning process (http://www.beachsamp.org/). Participants included property owners as well as those representing organizations, businesses, and neighborhood associations, as well as educational institutions, professional associations and other groups not captured in the Update. This intensely process-oriented approach has been a characteristic of Rhode Island coastal management since its inception, but also strongly supported by the work of Moser and Ekstrom analyzing lessons from San Francisco Bay experience. [18]. Yet there may be a participation divide acting as a barrier to adaptation. We explore this in Section 5. 


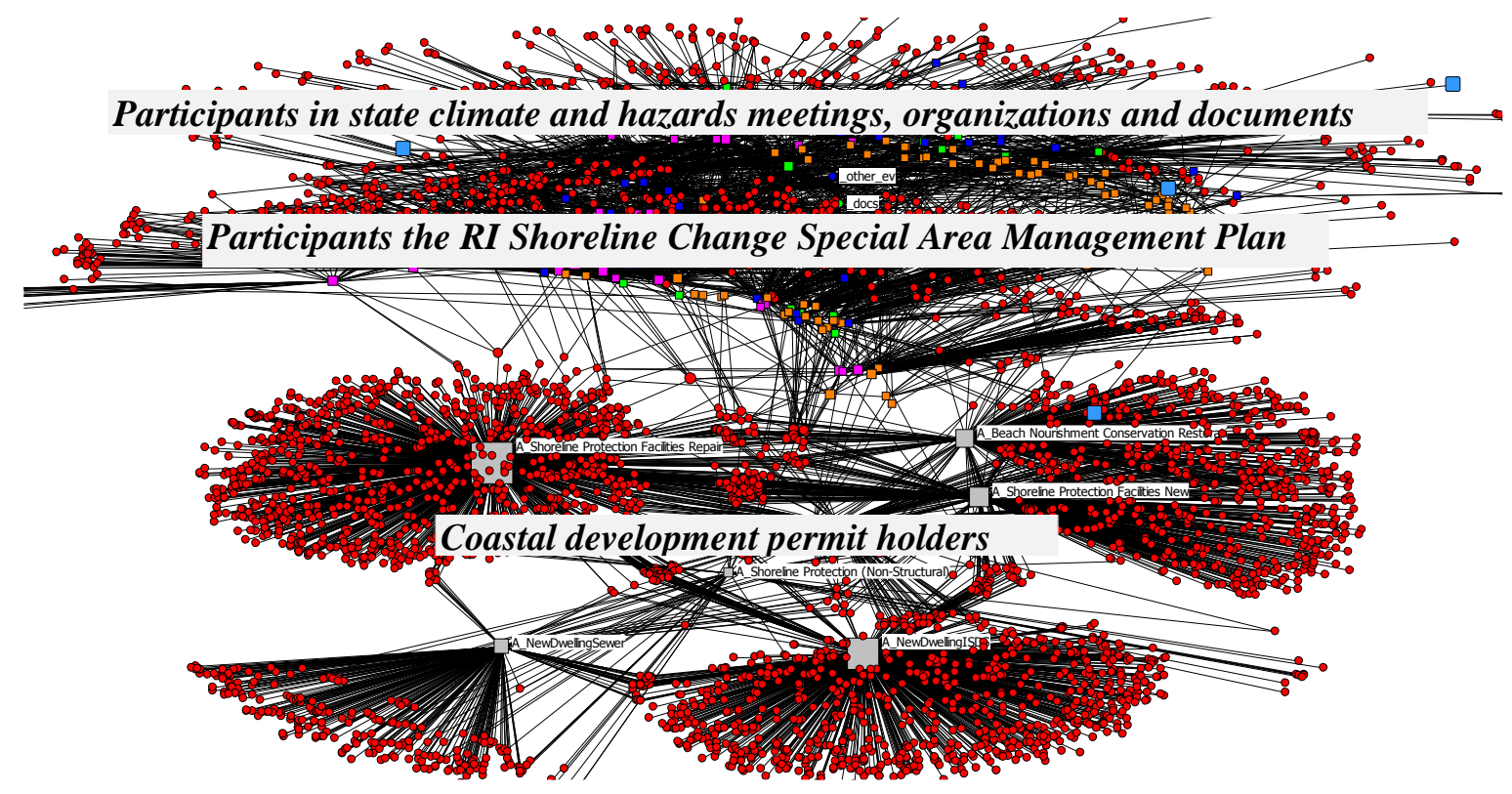

Figure 5 Social network analysis showing stratification and weak ties between the state level climate change and hazards actors (upper tier), stakeholders engaged in the RI Shoreline Change Special Area Management Plan (middle tier) and CRMC permit recipients for shore protection and new coastal dwellings state-wide (lower clusters)

Notes: The red dots in the sociogram represent individuals, while colored squares identify the meetings, reports, events and types of permits that individuals are affiliated with.

\section{The participation divide: a structural obstacle to stakeholder engagement and adoption of policy innovations}

Is Rhode Island's high level of public engagement actually reaching and influencing all those who are actually facing difficult current and future decisions regarding their homes and businesses located in high hazard areas?

We identified individuals involved in recent public events primarily in the present decade related to natural hazards and climate change, including publicly posted meeting minutes, reports, plans and other publications, attendance lists at Beach SAMP and other public meetings and workshops as well as the individuals holding coastal permits for shore protection and new homes.

The method of social network analysis we used to represent relationships is referred to as affiliation network or two-mode analysis. [19] It is based on the idea that individuals who meet or are involved in an 'event', such as a meeting, project, document, online meeting, and so on, have some kind of relationship. We combined this information with data from documents, news coverage and coastal development permit applicants statewide. The resulting socio-gram shown in Figure 5 includes 3833 individuals tied together by 57 events, 88 organizations as well as 4562 shore management and dwelling permits. (Individuals often are tied to multiple permit decisions.)

One surprise in this analysis is the apparent divide, between the individuals identified who are engaged in policy and planning activities on a regular basis; those who participated in the 2018 Beach SAMP; and those are actually living along the shore and hold permits.

Actors engaged in ongoing resilience policy debates as identified through documents, event participation and responsible organizations, form the top layer of the network. The Beach SAMP process included a series of 30 events held around the state from 2015 to 2018, engaged many of those already involved brought in hundreds of new people as well. However, very few of the individuals holding permits for shore protection or new development could be determined to have participated in the Beach SAMP process or otherwise engaged in meetings related to coastal and natural hazards resilience by other state and municipal entities. For example, only nine individuals, businesses and organizations with shoreline protection type permits from the CRMC in the hotly debated Matunuck situation are mentioned in the decades of news coverage of how the village is coping with coastal hazards. None of these local 
entities and actors appeared to be at all engaged in state-level policy and planning efforts.

One important group acting as a link between planning efforts and actual experience with shore protection and coastal development are coastal municipal governments. Cities and towns are struggling to determine how to maintain public infrastructure and recreational facilities in the face of sea level rise, erosion and a future major hurricane disaster, along with balancing conflicting priorities of maintaining public safety and promoting coastal development and maintaining an adequate tax base.

Another key group is largely hidden in this analysis: the dozens of builders, financers, legal, architectural and engineering consultants who frequently attend planning meetings and act in the background as key intermediaries between regulators, planners and property owners. More needs to done to understand the views and roles played by this group.

\section{A Century of coastal change and conflict in Matunuck Beach: an approach to understanding stakeholder views on resilience.}

Matunuck has been the locus of coastal management challenges and controversies since the 1970s, but more importantly has been a unique community and summer colony since the mid-1800s. The 2015 Matunuck Village Plan Prepared by Horsley Witten Group [20] sets out a detailed portrayal of its enduring value as a place for recreation, vacation homes and permanent residences. The social and recreational aspects of Matunuck are usually the focus for the seaside village, but the natural features that shape the landscape and provide habitat are also integral to the experience of Matunuck. Most recently, larger forces have become the center of attention as ocean currents and storms are reshaping Matunuck in dramatic ways. [20, p. 6].

According to the recently completed Shoreline Change Special Area Management Plan (SAMP) adopted by the Rhode Island Coastal Resources Management Council, the Matunuck Headland area is one of the most at risk in the state to the combined effects of storm surge, sea level rise and coastal erosion. An evaluation of historic shoreline change revealed a very high rate of erosion along a stretch of Matunuck from Cards Pond to the east end of South Kingstown Town Beach, with losses up to 1.4 meters/year. [4, Chapter 4, p. 52]

We compiled several dozen reports, plans and published studies, along with several hundred newspaper articles from 1983 to 2017 obtained using the simple search string "Matunuck AND erosion OR flooding". In addition, the full text of the Providence Journal and other Rhode Island based newspapers was searched and relevant articles downloaded.

We then used content analysis software, AtlasTi, to explore how all those who have written about or whose concerns and views have been documented view and express in their own terms the opportunities and obstacles carry out the content analysis.

An initial vocabulary of key terms and concepts was augmented by free coding as items were reviewed. This effort yielded 71 codes for quotes related to obstacles to adaptation, an equal number of codes covering adaptation responses, and 29 distinct codes for opportunities to adapt. Frequently mentioned obstacles, opportunities and action responses can be summarized as follows, in decreasing frequency of occurrence:

\section{OBSTACLES}

- Mismatch between impact causes and availability of effective solutions.

- Low comprehension of risk by property owners.

- Intense interest in extending the use of property in hazardous areas as long as possible.

- Strength of efforts to protect property and business investments.

- High cost of more effective solutions.

- Safety fears prompting urgent demands for quick action.

\section{OPPORTUNITIES}

- Ongoing state/ federal planning, zoning, regulation process.

- Public meeting or hearing.

- Coordination \& capacity for funding.

- Collaboration between private and government stakeholders.

- Congruence between nature of problem and most effective solutions.

- Educate private and public sector stakeholders. RESILIENCE RESPONSES:

- Shoreline protection (sea wall, sheet pile).

- Relocation of structures or activities.

- Proposed hazard policies and regulations.

- Temporary sand bags, fencing, wooden walls, burritos (fabric tubes).

- Beach nourishment (with material trucked in from outside).

- Beach nourishment related to local channel dredging projects.

Researchers, planners, regulators and stakeholders do not speak in "obstacles and opportunities" language. Our free coding rarely used actual phrases from stakeholders. For example, at a public hearing in April 2011, state and local officials met with a 
"roomful of disgruntled residents" to address the burgeoning conflicts over the degree of shore protection that should be allowed in a short section of Matunuck Beach road. [21]

The director of the State Coastal Resources Management Council stated that:

"... if he gives Matunuck what it wants, what does he say to other owners of shoreline properties who want to build sea walls? Hardened structures block the flow of sand and often cause more erosion of adjoining beaches."

"Kevin Finnegan of the Ocean Mist said much of the shoreline from Town Beach to East Matunuck State Beach is already hardened. The state should just finish the job, he said, or let property owners do it.

"Let me, Fran and the other property owners protect your road, said Finnegan, to big applause."

"South Kingstown manager Stephen Alfred said "only 65 feet of land remain between the ocean and Matunuck Beach Road. To me, we've got to look at how to protect the village and existing businesses. The longer we say we don $\mathrm{t}$ know how we're going to do it, the options become less and less. I haven't heard of other areas in Rhode Island where businesses are about to fall into the drink. "“

"Fran O'Brien of Tara's Joyce Family Pub said he wasn't asking for taxpayer help, he just wanted permission to protect his own property."

In coding these passages from the article we found at least eight distinct obstacles facing the decisionmaking conflict in Matunuck:

- $\quad$ need to demonstrate a public purpose for a hazard mitigation project.

- $\quad$ need for equitable resolution of conflicts.

- interest in extending the use of property in hazardous areas as long as possible.

- $\quad$ political pressure on decision makers.

- interest in protecting property, businesses and investments.

- $\quad$ safety fears leading to calls for quick action.

- limited availability of relocation sites.

- $\quad$ pressure to relax protective rules.

Although Matunuck stakeholders---including a town official---expressed the view that they are uniquely singled out for push-back from state authorities, no one is clamoring for more scientific information about whether there is a problem, rather the focus is on the decision time-horizon and the willingness by property owners to accept short to medium range actions.

There are many more connections and dynamics among the obstacles, opportunities and responses, but our aim here is to show broader ideas and patterns. The full set of obstacles, opportunities and responses can be arrayed around six broad categories: Process, Knowledge \& Attitudes, Situational Factors, Money \& Finance, Actions and Policy. The specific quotes captured for Matunuck cover the full range of drama, frustration and doubt raised each time a major storm event causes damage and concern in the community. In contrast, most public documents such as plans and studies shy away from a discussion of obstacles and focus on Knowledge, Action, and Process variables. The Shoreline Special Area Plan document is rich and thorough in its scientific treatment of Matunuck and other high priority segments of the shore, as well as detailed in its recommendations on adaptation actions. Yet the new plan is also constrained in its approach:

"The guidance offered by this Shoreline Change SAMP is primarily for applicants seeking coastal permits from CRMC. CRMC is proposing a requirement that coastal permit applicants complete a five-step risk assessment process for proposed developments within CRMC's jurisdiction as part of the permit application. [4]

The audience for the new SAMP includes decision makers, planners, boards and commissions in Rhode Island's 21 coastal communities who are principally responsible for coping with the impacts of storms, coastal erosion, and sea level rise outside of CRMC's jurisdiction. The SAMP is also intended to aid other state and federal agencies responsible for coastal resources, assets and property in Rhode Island in future planning and decision making. [4]

However, the continuing depth of conflict and resistance to some of Rhode Island's resilience measures produced a surprising policy result in mid2018 after the Beach SAMP was adopted. The RI General Assembly sided with environmentalists, the CRMC and builders---against staunch opposition of municipalities---to allow developers to measure maximum building height from the base flood elevation rather than ground level, creating much higher structures that will be resilient to flooding and storm surge but also leading to "plenty of uproar when building permits are pulled and neighbors see the size of beachfront homes to be built." [22] Even if current trends show a relatively low rate of new shorefront development within the Hurricane of '38 overwash zone, this policy could offer a strong incentive for wealthy property owners to acquire and demolish even more vulnerable structures and replace them with "McMansions" that meet legal requirements but block views, possibly lower property values in surrounding shore-side neighborhoods and increase the number of structures overall that are exposed to hazards. 


\section{Summary}

Numerous obstacles, opportunities and responses to climate and hazard resilience are present in Rhode Island, a coastal state without recent experience in responding to the type of major disaster represented by Hurricane Katrina, Matthew, Harvey, Maria, Matthew, Sandy and Florence. Rhode Island researchers and planners remain concerned about raising the level of public understanding of the combined effects of a historic level hurricane combined sea level rise and chronic coastal erosion as threats to coastal development and ecosystems. They are producing new information and approaches to visualization and conducting active stakeholder engagement and planning processes to create better policy and motivate coastal property owner and community response.

We employed three approaches to understand obstacles to and opportunities for resilience actions beyond the standard concerns about lack of knowledge and low comprehension of risk.

Our examination of coastal regulatory decisions indicates that there are dozens of segments or reaches of the RI coast where homeowners and businesses continue to struggle to maintain their properties in the face of localized threats from periodic storms, chronic erosion and rising sea level. Matunuck Beach is one of the most contentious of these locations and became a focus of our attention. The steady decline in requests for new housing construction or hardened shoreline protection on the shore has been replaced by property owners remodeling or rehabilitating older properties to extend their usable life in the face of hazards. Now they have the added incentive of being able to raise these old structures above flood elevation without violating local zoning ordinances. Neither education, online mapping tools, frightening scenarios nor the potential of loss of access to flood insurance may not deter this group from causing a surge in coastal development.

Our assembly of social network data confirms that Rhode Island's recent effort to create a new set of guidelines for vulnerable areas, the Beach SAMP, succeeded in expanding stakeholder awareness and engagement in resilience planning, particularly among municipal authorities. However, state planning efforts are not reaching the far greater number of individuals and businesses already located in the shore, possessing shore protection permits and continuing to facing chronic property damage. The efforts may not be reaching those who are rehabilitating or seeking to construct new homes in the most vulnerable areas.

Hidden from view in the present analysis are the highly influential group of builders, financers and consultants who work with property owners to navigate the evolving universe of information, plans, regulations and characteristics of hazardous coastal sites to meet their clients' expectations. Evidence of their broader influence on RI resilience policy emerged in the surprise adoption in July 2018 of the dramatic change to measuring base elevation of properties in coastal areas to allow elevation of coastal structures to proceed more rapidly.

Our analysis of the content of documents and press reports on coastal hazards, focusing on the continuing conflict in Matunuck Village, indicates that the plain language that is used by stakeholders to express frustration and even resistance to resilience initiatives is not readily captured in any of the analytical schemes used by resilience researchers, including our own. Coastal property owners and public officials facing damage to public infrastructure have a broad range of concerns and sometimes conflicting goals that lie well beyond the need for better understanding that needs to be remedied by yet more scientific and site based information or by improvements in the planning and stakeholder engagement process. Those who are determined to protect their shorefront investments argue for an unconstrained right to do so while those with ample funds and a determination to remain or locate in the coast want clear rules to comply with, however expensive.

Coastal residents and business owners who are willing to retreat or relocate after a major storm or in the face of chronic impacts, are still searching---so far in vain---for acceptable, feasible, and affordable alternatives while they still have time to act.

\section{Acknowledgements}

This material is based upon work supported by the U.S. Department of Homeland Security under Grant Award Number 2015-ST-061-ND0001-01. The views and conclusions contained in this document are those of the authors and should not be interpreted as necessarily representing the official policies, either expressed or implied, of the U.S Department of Homeland Security. Dawn Kotowicz Ph.D. is coinvestigator for this research. Support also was provided through the URI Coastal Institute and the Rhode Island CRMC. Ryan Moore of the CRMC provided the permit data, CRMC Director Grover Fugate and CRMC Assistant Director Jeff Willis for reviewing initial findings. Courtney Corvese of the Coastal Resources Center and Courtney Hill of Tougaloo College assembled information for the initial social network as well as CRMC permit data visualizations. We also thank the four anonymous reviewers of the original submission who recommended a number of helpful revisions. 


\section{References}

[1] Johansen, C., Horney, J., Tien, I. (2017). Metrics for Evaluating and Improving Community Resilience. Journal of Infrastructure Systems. Volume 23 Issue 2 - June 2017

[2] U.S. Army Corps of Engineers. (2012). The Quantification and Evolution of Resilience in Integrated Coastal Systems, Flood and Coastal Storm Damage Reduction Program, ERDC TR-12-7 (August).

[3] Rhode Island Emergency Management Agency. (2017). State of Rhode Island Hazard Identification and Risk Assessment. Providence, RI: Rhode Island Emergency Management Agency.

[4] Coastal Resources Management Council. (2018). Shoreline Change Special Area Management Plan. Narragansett, RI: Rhode Island Coastal Resources Management Council. http://www.beachsamp.org/

[5] Mundorf, N., Redding, C., Prochaska, J., Paiva, A., Rubinoff, P. (2018) Resilience and Thriving in Spite of Disasters: A Stages of Change Approach. In Fekete, A., \& Fiedrich, F. (2018). Urban disaster resilience and security: Addressing risks in societies. Cham, Switzerland : Springer, pages 383-396.

[6] Burton I., (2009). "Climate Change and the Adaptation Deficit". Earthscan Reader on Adaptation to Climate Change, eds. Schipper ELF, Burton I (Earthscan, Sterling, VA), pp 89-95.

[7] Smith, G., Martin, A., Wenger, D. (2018) Disaster Recovery in an Era of Climate Change: The Unrealized Promise of Institutional Resilience, Chapter 28. In Handbook of Disaster Research, Eds. Havidán Rodríguez, William Donner and Joseph E. Trainor. Cham, Switzerland, Springer.

[8] Moser, S. C. and J. A. Ekstrom, (2014). "A framework to diagnose barriers to climate change adaptation". Proc. Natl. Acad. Sci. 107, 22026-22031(2014).

[9] Deegan, M. (2011). "Using Causal Maps to Analyze Policy Complexity and Intergovernmental Coordination: An empirical study of floodplain management recommendations". Proceedings of the 29th International System Dynamics Conference, Washington, D.C.

[10] Mileti, D.S. (1999). Disasters by Design: A Reassessment of Natural Hazards in the United States,Joseph Henry, Washington, DC.

[11] Birkland, T. (2006). Lessons of Disaster: Policy Change after Catastrophic Events. Washington, DC: Georgetown University Press.

[12] Burby, R. (2006). Hurricane Katrina and the Paradoxes of Government Disaster Policy: Bringing About Wise Governmental Decisions for Hazardous Areas. The Annals of the American Academy of Political and Social Science 604 (1):171-191.

[13] Berke, P., Newman, G., Lee, J., Combs, T., Kolosna, C. and Salvesen, D. (2015) Evaluation of Networks of Plans and Vulnerability to Hazards and Climate Change: A Resilience Scorecard, Journal of the American Planning Association, 81:4, 287-302.

[14] Becker, A. (2017) Using boundary objects to stimulate transformational thinking: storm resilience for the Port of Providence, Rhode Island (USA) Sustainability Science; Dordrecht Vol. 12, Iss. 3, (May 2017).

[15] Small, C., Blanpied, T., Kauffman, A., O’Neil, C., Proulx, N., Rajacich, M., Simpson, H., White, J., Spaulding, M.L., Baxter, C.D. and Swanson, J.C., (2016) Assessment of Damage and Adaptation Strategies for Structures and Infrastructure from Storm Surge and Sea Level Rise for a Coastal Community in Rhode Island, United States. J. Mar. Sci. Eng. 2016, 4(4), 67; doi:10.3390/jmse4040067.

[16] Rhode Island Emergency Management Agency. (2014). State of Rhode Island Hazard Mitigation Plan Update. Providence, RI: Rhode Island Emergency Management Agency.

[17] Spaulding ML, Grilli A, Damon C, Crean T, Fugate G, Oakley BA, Stempel P (2016). STORMTOOLS: coastal environmental risk index (CERI). J Mar Sci Eng 4(3):54.

[18] Moser, Susanne C., and Julia A. Ekstrom. (2012). Identifying and Overcoming Barriers to Climate Change Adaptation in San Francisco Bay: Results from Case Studies. California Energy Commission. Publication number: CEC-500-2012-034.

[19] Borgatti, S. P., Everett, M., Johnson, J. C..(2013). Analyzing Social Networks. Thousand Oaks, CA: Sage.

[20] Horsely Witten Group. (2015). The Matunuck Village Plan.

http://www.horsleywitten.com/skingstownvillagestudy/pdf/ Matunuck_Village_Plan_Report.pdf Accessed June 15, 2018 .

[21] Lord, P., Smith, A. (2011) State's shifting sands. Providence Journal, April 11, 2011, p. 1.

[22] Rhode Island General Assembly. (2018). H 7741 Substitute A. An Act Relating to Towns and Cities Zoning Ordinances, amending Section 45-24-31 of the General Laws in Chapter 45-24 to allow building height to be measured from base flood elevation but excluding freeboard requirements. 